\title{
Cognitive Understanding of Object Permanence in Mandrills (Mandrillus $\operatorname{sphinx,~L.)~}$
}

\author{
Anna Gabel, Carsten Lucass, Stefanie M. Zimmer, Christina Bietz, Maren Schwenke and \\ Ralf Wanker ${ }^{*}$
}

Biozentrum Grindel, University of Hamburg, Martin-Luther-King Platz 3, 20146 Hamburg, Germany

\begin{abstract}
Object permanence tests are a standard procedure to test the cognitive ability to mentally follow a hidden object. To test this capacity in mandrills, we used visible and color-tracking with invisible displacement tests. During visible displacement the object was hidden and moved within its container in full view of the tested individual. During color-tracking with invisible displacement the object was hidden in a colored container, also in full view, but then moved within its container out of view. The tested mandrills were successful in the visible but not in the color-tracking with invisible displacement tests. They did not use the color as a cue for the correct container. One of the animals memorized the position of the container, in which the reward was dropped before the invisible displacement. We assume that the capacity of solving invisible displacement tests has evolved after the evolutionary separation of mandrills and apes.
\end{abstract}

\section{INTRODUCTION}

Object permanence is an aspect of cognition and is defined as the ability to mentally follow a hidden object [1]. There are two main tasks to test this cognitive ability, the visible and the invisible displacement. During visible displacement an object is hidden in a container in full view of the tested individual whereas during invisible displacement the object is first hidden in a container and then the container is moved. Piaget defined six stages in which these abilities developed from simplest reflexes to mental representation [1]. For example, in stage $4 \mathrm{~b}$ of object permanence, individuals succeed in this visible displacement task, but fail when the object is hidden in various places during sequential trials because they search in the previously successful place. At stage 5a the subjects are able to solve sequential visible displacements. At stage $5 \mathrm{~b}$ subjects can solve single invisible displacements and stage 6a marks the beginning of solving sequential invisible displacements. At stage $6 \mathrm{~b}$ subjects can mentally reconstruct the movements of an unperceived object [2]. Based on tests of human infants, Piaget concluded that 9-month old children lack the ability of object permanence [1]. However, Baillargeon and co-workers [3] found that 5-month old infants understand that an object still exists when it is hidden, but lack the short term memory to fulfil the task.

Piaget's experiments were slightly modified and adjusted to animals. For instance, rhesus macaques and squirrel monkeys succeeded in the visible displacement tests but in invisible displacement tests they showed a preference for the position of the container in which the reward was previously hidden [4]. Cotton-top tamarins were also more successful in solving visible than invisible displacement tests [5]. In a recent study, Fedor and co-workers [6] conducted single

*Address correspondence to this author at the Biozentrum Grindel, University of Hamburg, Martin-Luther-King Platz 3, 20146 Hamburg, Germany; E-mail: wanker@zoologie.uni-hamburg.de visible, single invisible, double invisible, and control displacements with 10 gibbons of different species [7]. The performance of the gibbons was better than would be expected by chance, except for the double invisible displacement where the object is hidden twice in two adjacent boxes standing in a linear array. There was a high degree of variability in performance across the subjects. Orangutans were also able to solve all tasks successfully, except for the double invisible displacement test [4]. Among mammals, until now, only apes and domesticated dogs are able to solve invisible displacement tests. Apes have the capacity to mentally represent the invisible displacement, i.e. to visualize the invisible trajectory of the hidden object [8]. For instance, the ability of chimpanzees to mentally represent single invisible displacements can be compared to that of 18 24-month old children [9]. Dogs, on the other hand, could solve the invisible displacement test but do not seem to have the same representational ability as apes [10]. Their search behavior is guided by simple associative rules rather than mental representation of the object's past trajectory, i.e. the dog creates an association between the object and the container that was manipulated by the experimenter.

We wanted to know if mandrills, an old world monkey species living in groups in the tropical rain forests of WestAfrica, are able to solve visible and invisible displacement tests. We therefore conducted different series' of tests with different degrees of complexity according to the stages of Piaget. As color perception should be evident in these animals, to estimate the ripeness of fruits [11], we used containers of different colors in our invisible displacement experiments, to test if mandrills use color as a cue to follow the hidden objects.

\section{MATERIALS AND METHODS}

\section{Study Animals}

We conducted two series' of object permanence tests. The first series of visible displacement tasks was done in 
April 2007 and the second series of invisible displacement tests was done, with the same group of mandrills, in April 2008. During the study, the group of mandrills consisted of 25 individuals living together in an enclosure in the Tierpark Hagenbeck, Hamburg, Germany. In the first tests 5 individuals could be tested (female Abba, 12 years, and males Bates, 7 years; Twig, 5 years; Joker, 5 years and Tika, 4.5 years) and in the second test series three males (Twig; Furche, 3 years and Schwarznase 3 years). All animals participated actively and voluntarily, without being forced to approach the experimental setup. The study animals were living in an L-shaped outdoor-enclosure $\left(330 \mathrm{~m}^{2}\right)$, which was connected to an indoor-enclosure of $63 \mathrm{~m}^{2}$. The mandrills were fed four times daily, with their nutrition consisting of fruits and vegetables as well as provender. Fruits and vegetables were given in the early morning, at noon and in the afternoon, and the provender was given at 12:30 p.m. to keep the animals busy.

\section{Experimental Setup}

\section{General Setup}

The experiments were conducted on one side of the outdoor-enclosure that was not accessible for visitors. The animals could freely move between the enclosures, and they were not separated from the group during the experiments. The tests were conducted on several days, before the midday-feeding.
The experimental equipment consisted of a one-meter wooden board with three lines marking the positions left, middle and right, which was positioned on a bench in front of the outdoor-enclosure. Three non-transparent cylindrical containers were placed on the marks. The containers were made of manipulated hard-plastic tubes with a diameter of 8 $\mathrm{cm}$ and a height of $12 \mathrm{~cm}$. The tubes were closed on the bottom side and half-opened on the top side so that the animals could not look inside and had to grab the tube in order to obtain the reward. The reward, a piece of apple, banana or pear, or a grape or peanut, was placed by the experimenter in one of the containers which was chosen randomly with a dice. This could be observed by the test subject, but the board with the containers was out of reach. After manipulation (see below) the wooden board with the containers was moved into the direct reach of the monkeys. To prevent gaze following or other cues the experimenters could give, they used sunglasses and a baseball cap. We recorded which container was chosen by the tested animal. All tests in which the study animal was distracted by visitors, keepers or conspecifics were not included in the analysis.

\section{Manipulation During Visible Displacement}

The containers were all grey-colored. Tests were performed in three stages: stage 1 , two containers at each end of the wooden board, no change of position; stage 2 , as in stage 1 but the positions were changed after the reward was hidden in one container; stage 3 , three containers on the board (left, middle, right) and the position of the container

a.
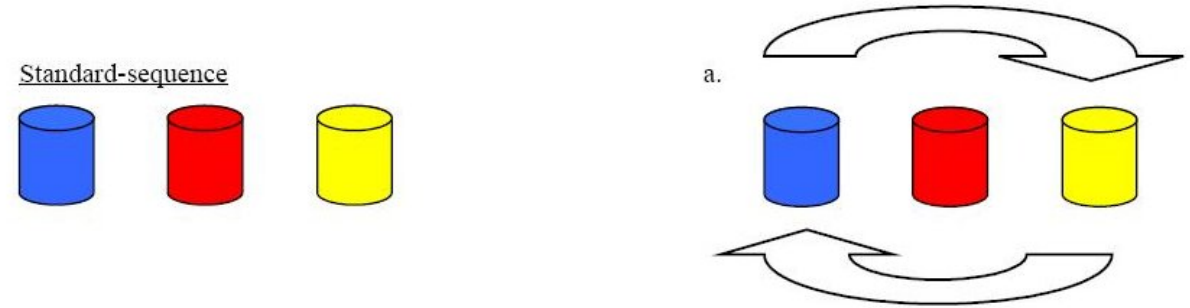

c.

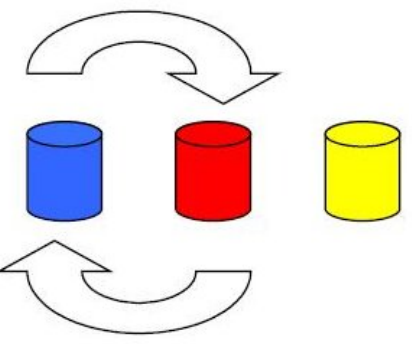

b.

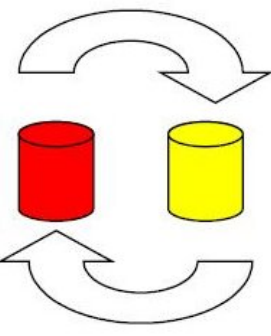

d.

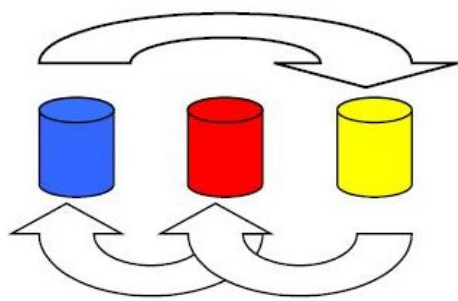

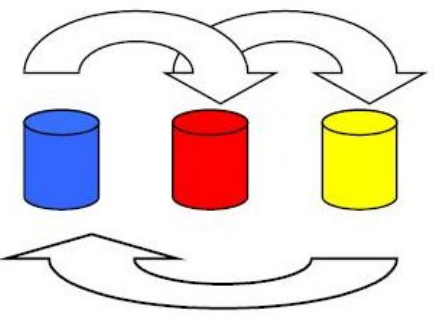

Fig. (1). Standard-sequence and possible modification patterns of the three colored containers. 
with the reward was changed with each of the empty containers resulting in two changes in random order.

For statistical analyses we used the G-test to test for homogeneity.

\section{Manipulation During Color-Tracking with Invisible Displacement}

The containers were red, blue and yellow in color and were placed in a standard order on the marks of the wooden board. During these tests, we used only peanuts as a reward. These were placed inside one randomly-chosen container. Subsequently, behind a big carton, the order of the containers was modified systematically (Fig. 1). After modifying the sequence of the containers, the carton was removed and the board was moved into operating distance of the mandrill. The animals could not infer what movements were performed behind the screen. Their task was to remember the appropriate color after the screen was removed and to understand that the container with the reward had been moved behind the screen.

The analysis was split in two parts. First, we analyzed if the subject chose the container with the peanut ("Correct") or one of the two empty containers ("False"). Second, we analyzed if the animal selected (a) the container placed on the position (left - middle - right) where the peanut was dropped into a container before modifying the standardsequence ("Position"), (b) the container with the correct color containing the peanut ("Color") or (c) neither the container standing on the position where the peanut was dropped nor the one with the correct color containing the reward ("Without any attribute"). Because position and color were the same when the baited container was not moved, we did not include these cases into the analysis. Thus the number of tests analysed differ between the two analyses.

For statistical analyses we used the $\chi^{2}$-test to test for homogeneity, with $\mathrm{N}$ being the number of trials.

\section{RESULTS}

\section{Visible Displacement}

During all three stages the mandrills chose significantly more often the correct container (stage $1, \chi^{2}=20.815, \mathrm{~N}=5$, $\mathrm{p} \leq 0.001 ;$ stage $2, \chi^{2}=33.589, \mathrm{~N}=5, \mathrm{p} \leq 0.05 ;$ stage $3, \chi^{2}$ $=10.86, \mathrm{~N}=3, \mathrm{p} \leq 0.05$; see Table $\mathbf{1}$ ).

Table 1. Results of the Visible Displacement Tests

\begin{tabular}{|c|c|c|c|c|c|c|}
\hline \multirow{2}{*}{ Subjects } & \multicolumn{2}{|c|}{ Stage 1 } & \multicolumn{2}{c|}{ Stage 2 } & \multicolumn{2}{c|}{ Stage 3 } \\
\cline { 2 - 7 } & Correct & False & Correct & False & Correct & False \\
\hline \hline Tika & 26 & 1 & 43 & 8 & 37 & 4 \\
\hline Joker & 17 & - & 50 & 4 & 15 & 1 \\
\hline Abba & 13 & - & 8 & 11 & 2 & 3 \\
\hline Bates & 13 & 7 & 7 & 7 & - & - \\
\hline Twig & 2 & 2 & 2 & 4 & - & - \\
\hline
\end{tabular}

\section{Color-Tracking with Invisible Displacement}

All three study subjects selected more often one of the empty containers than the container with the peanut inside. However, this result was statistically nonsignificant (Schwarznase: $\chi^{2}=0,08 ; \mathrm{N}=37$; n.s.; Twig: $\chi^{2}=0,071 ; \mathrm{N}=$ 110; n.s.; Furche: $\chi^{2}=0,36 ; \mathrm{N}=130$; n.s.; see Table 2).

Table 2. Results of the Color-Tracking with Invisible Displacement Tests with the Three Tested Animals

\begin{tabular}{|c|c|c|}
\hline Subjects & Correct & False \\
\hline \hline Schwarznase & 14 & 23 \\
\hline Twig & 34 & 76 \\
\hline Furche & 37 & 93 \\
\hline
\end{tabular}

Schwarznase did not show a preference either for the position or the color of the container $\left(\chi^{2}=0,06 ; \mathrm{N}=37\right.$; n.s.). Twig $\left(\chi^{2}=2,22 ; N=110 ;\right.$ n.s. $)$ and Furche $\left(\chi^{2}=16,06\right.$; $\mathrm{N}=130 ; \mathrm{p}<0,05)$ more often chose the container standing on the position where the peanut was dropped before modifying the standard-sequence (see Table 3). However, only Furche's results were statistically significant.

Table 3. Preference for Color or Position of the Three Tested Animals in the Color-Tracking with Invisible Displacement Tests

\begin{tabular}{|c|c|c|c|}
\hline Subjects & $\begin{array}{c}\text { Position } \\
\text { preferred }\end{array}$ & $\begin{array}{c}\text { Color } \\
\text { preferred }\end{array}$ & $\begin{array}{c}\text { Without any } \\
\text { attribute }\end{array}$ \\
\hline \hline Schwarznase & 11 & 11 & 13 \\
\hline Twig & 46 & 22 & 30 \\
\hline Furche & 76 & 15 & 16 \\
\hline
\end{tabular}

\section{DISCUSSION}

The results of this study show that the mandrills are able to solve visible displacement tests of different complexity, but were unable to solve the invisible displacement tests. None of the subjects recognized the manipulated order of the three containers in the invisible displacement task, although they were marked with different colors. From our results we can conclude that they are capable of mentally following the visible displacement of hidden objects. But they are not capable to mentally reconstruct the movements of an unperceived object. Furthermore, they were not able to memorize the color of the container where the object was hidden.

According to Piaget's scale [1], mandrills would be at stage 5a and could be compared to human children in their tenth month of life. If we take a look on the other primates tested so far, we can arrange them on a scale using Piaget's stages. Rhesus macaques and squirrel monkeys are at stage 5a [4] together with cotton top tamarins, which were better in visible than in invisible displacement [5]. Gibbons and 
orangutans are at stage $5 b[4,6]$ and chimpanzees are at the beginning of stage $6 \mathrm{~b}$, the same as 18-24-month old human children [9]. In this list, mandrills could be arranged together with rhesus macaques and cotton top tamarins. So the evolutionary step from stage 5 to stage 6 , i.e. from the understanding of visible to invisible displacement should have happened early in the phylogeny of monkeys and apes.

Mandrills are probably not capable of solving the invisible displacement tests because they are not confronted with this set of problems in their natural environments. It seems possible that visible displacement is a common problem in their daily life; for example, when prey is vanishing into a hide. One of the subjects, Furche, chose significantly more often the container standing on the position where the peanut had been dropped into the container. This suggests that this mandrill memorized the position into which the reward was dropped rather than keeping in mind the color of the container. Twig also tended to more frequently choose the container on the position where the reward had been placed. Thus, they reacted as if the containers had not been moved.

This study has shown that mandrills are able to solve visible displacement tests successfully but fail to solve invisible displacement tests. Thus, they could be assigned to stage 5a of Piaget's scale of object permanence showing the cognitive capacities of a 10-month old human child.

\section{ACKNOWLEDGEMENTS}

We thank the management of Tierpark Hagenbeck and Jutta Schneider for giving us the opportunity to conduct this study and specially keeper Tony Kershaw for introducing us to the mandrills. Anna Fedor and two anonymous referees provided helpful comments on an earlier draft of the manuscript

\section{REFERENCES}

[1] Piaget J. The Construction of Reality in the Child. New York: Basic Books Inc. 1954.

[2] Doré FY, Dumas C. Psychology of animal cognition: Piagetian studies. Psychol Bull 1987; 102: 219-33.

[3] Baillargeon R, Spelke ES, Wasserman S. Object permanence in five-month-old infants. Cognition 1985; 20: 191-208.

[4] De Blois ST. Object permanence in three species of primates: Rhesus monkeys (Macaca mulatta), squirrel monkeys (Saimiri sciureus), and orangutans (Pongo pygmaeus). Ph.D. Thesis. University of Massachusetts, Amherst 1997.

[5] Neiworth JJ, Steinmark E, Basile BM, Wonders R, Steely F, DeHart C. A test of object permanence in a New World monkey species, cotton top tamarins (Saguinus oedipus). Anim Cogn 2003; 6: 27-37.

[6] Fedor A, Skollar G, Szerencsy N, Ujhelyi M. Object permanence tests on gibbons (Hylobatidae). J Comp Psychol 2008; 122: 403-17.

[7] Collier-Baker E, Suddendorf T. Do chimpanzees (Pan troglodytes) and 2-year-old children (Homo sapiens) understand double invisible displacement? J Comp Psychol 2006; 120: 89-97.

[8] Collier-Baker E. Invisible displacement understanding in dogs (Canis familiaris), chimpanzees (Pan troglodytes), and other primates. Ph.D. Thesis. School of Psychology: The University of Queensland, Australia 2006.

[9] Collier-Baker E, Davis JM, Nielsen M, Suddendorf T. Do chimpanzees (Pan troglodytes) understand single invisible displacement? Anim Cogn 2006; 9: 55-61.

[10] Collier-Baker E, Davis JM, Suddendorf T. Do dogs (Canis familiaris) Understand invisible displacement? J Comp Psycho 2004; 118: 421-33

[11] Jacobs GH. Primate photopigments and primate color vision. Proc Natl Acad Sci USA 1996; 93: 577-81.

\section{Received: January 01, 2009 \\ (C) Gabel et al.; Licensee Bentham Open.}

This is an open access article licensed under the terms of the Creative Commons Attribution Non-Commercial License (http://creativecommons.org/licenses/by$\mathrm{nc} / 3.0 /$ ), which permits unrestricted, non-commercial use, distribution and reproduction in any medium, provided the work is properly cited. 